\title{
BURIED ANCIENT FOREST AND IMPLICATIONS FOR PALEOCLIMATE SINCE THE MID-HOLOCENE IN SOUTH CHINA
}

\author{
C D Shen ${ }^{1,2,3} \bullet \mathrm{P}_{\text {Ding }}^{1} \bullet \mathrm{N} \mathrm{Wang}^{1} \bullet \mathrm{W} \mathrm{X} \mathrm{Yi}{ }^{1} \cdot \mathrm{X} \mathrm{F} \mathrm{Ding}^{2} \bullet \mathrm{D} \mathrm{P} \mathrm{Fu}^{2} \bullet \mathrm{K} \mathrm{X} \mathrm{Liu}{ }^{2} \bullet \mathrm{L} \mathrm{P} \mathrm{Zhou}^{4}$
}

ABSTRACT. The historical evolution of an ancient forest that developed at Gaoyao, south China, can be divided into 4 stages of radiocarbon intervals (1.1-1.5, 2.0-3.5, 3.6-4.0, and 4.3-4.9 ka) in which the last 3 stages all developed in a wetland and formed humic layers of 2.0, 0.5 , and $0.7 \mathrm{~m}$ depth, respectively. The humic layers were interrupted by 2 white-gray silty clay layers that most likely formed during climate fluctuations. Four drought events were identified during the evolution of the ancient forest, occurring around 4.3, 3.6, 2.0, and $1.1 \mathrm{ka}$, respectively, with durations of $\sim 1000{ }^{14} \mathrm{C}$ yr. These events are consistent with other records both in low- and high-latitude areas, in particular with the little ice ages occurring since the midHolocene. Precipitation likely increased from 5.0 to $3.6 \mathrm{ka}$ in south China, then decreased, which is probably the main cause for the development as well as the demise of the ancient forest.

\section{INTRODUCTION}

Coherent high- and low-latitude climate variability during the Holocene has been widely reported from corals, marine and lake sediments, and stalagmite records (deMenocal et al. 2000; Bond et al. 2001; Yu et al. 2002; Wang et al. 2005). However, evidence for unstable Holocene climate in southern China is still limited, and the interpretation of recently published high-resolution lake records is still under debate (Yancheva et al. 2007; Zhang and Lu 2007; Zhou et al. 2007). Here, we report results of an investigation on a 5.7-m-thick record of buried tree remains from the Gaoyao site in subtropical China.

In south China, especially in the Pearl River Delta, many well-preserved ancient forests dominated by Glyptostrobus pensilis were found buried underground. G. pensilis is a hydrophilous plant that prefers to grow along a river bank or wetland under warm climate conditions ( $\mathrm{Li}$ and Xia 2004). Although the buried forests are potentially useful for paleoclimate studies, very little is known about their historical evolution. Li et al. (2001) investigated buried timbers around Guangdong Province and suggested that a cooling equivalent to the "little ice age" during the Holocene probably caused the death of the ancient trees. Zong (2004) argued that the marine inundation around 3.0 ka was probably responsible for the disappearance of the ancient forests. However, there is a lack of accurate chronological controls on these studied ancient forests. In a more recent study at Sihui, south China, we have shown that lower precipitation was probably the main reason for the disappearance of the wetland and associated ancient forest (Ding et al. 2009). Compared to the buried forests at Sihui, the ancient forests at Gaoyao are more complicated. They consist of several development stages, and their development was interrupted 3 times. Therefore, we expect the buried forest profile at Gaoyao to provide more detailed information about local climate change. In this study, we first establish the ${ }^{14} \mathrm{C}$ chronology for the buried ancient forest at Gaoyao, then discuss the paleoclimate implications of variations in the content of the organic carbon and the composition of stable carbon isotopes $\left(\delta^{13} \mathrm{C}\right)$.

\footnotetext{
${ }^{1}$ Key Laboratory of Isotope Geochronology and Geochemistry, Guangzhou Institute of Geochemistry, Chinese Academy of Sciences, Guangzhou 510640, China.

${ }^{2}$ State Key Laboratory of Nuclear physics and Technology, Peking University, Beijing 100871, China.

${ }^{3}$ Corresponding author. Email: cdshen@gig.ac.cn.

${ }^{4}$ Laboratory for Earth Surface Processes, Department of Geography, Peking University, Beijing 100871, China.
}

(C) 2010 by the Arizona Board of Regents on behalf of the University of Arizona Proceedings of the 20th International Radiocarbon Conference, edited by A J T Jull RADIOCARBON, Vol 52, Nr 2-3, 2010, p 1411-1421 

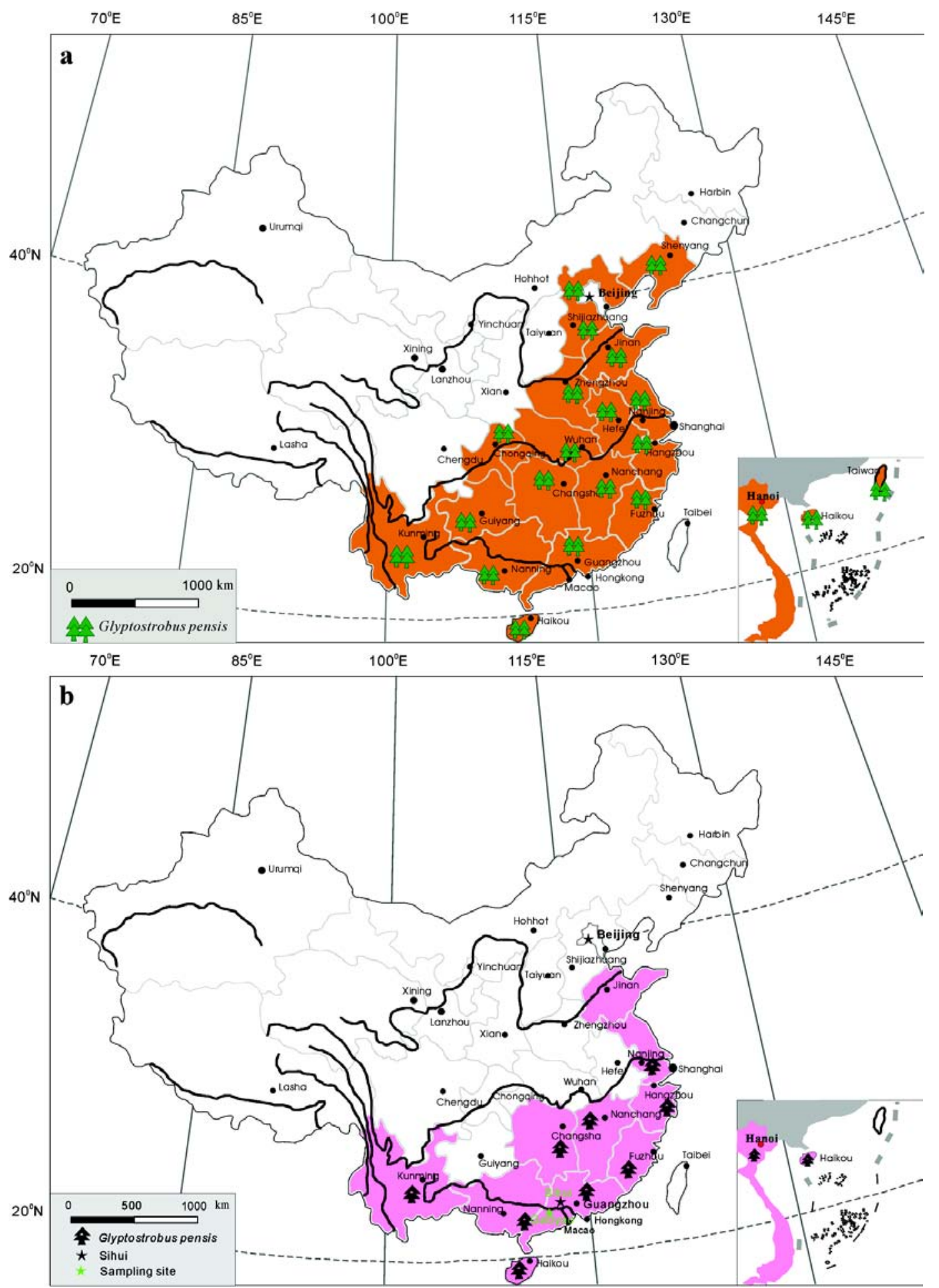

Figure 1 Map of historical (a) and present (b) distribution of Glyptostrobus pensilis, according to Li and Xia (2004). The green star in (b) marks the sampling location at Gaoyao, south China. 


\section{SAMPLING AND METHODS}

\section{Historical and Present Distribution of Glyptostrobus pensilis in China}

Glyptostrobus pensilis once covered much wider areas in the Northern Hemisphere, including the high Arctic in the Paleocene. According to fossil finds of G. pensilis, it was widespread along the coastal region of north, central, and southern China (Figure 1a) with more than 6 species during the peak periods ( $\mathrm{Li}$ and Xia 2004). However, the plant was reduced to its current range before and during the ice ages. Today, the species is nearly extinct in the wild-only a few to tens of trees remain in a given area with only 1 species (Taxodiaceae) — and is mainly concentrated in southern China and Vietnam (Figure 1b; Li and Xia 2004).

The reduction of the G. pensilis distribution range can be attributed mainly to climate variation. During the ice ages in the Quaternary, lower temperatures and less precipitation impelled the range of these plants southward. Hence, the present distribution of G. pensilis mainly concentrated in the wet climate areas with abundant precipitation also indicates the impact of climate, especially that of precipitation, on the plant (Figure 1b).

\section{Location Description}

Gaoyao is located in central Guangdong Province, west of the Pearl River Delta (Figure 1b). It belongs to a subtropical monsoon climate zone with a mean annual precipitation of $\sim 1900 \mathrm{~mm}$ and an average annual temperature of $21^{\circ} \mathrm{C}$. April through September is the rainy season, while November to January is the dry season (Yu and Peng 1995). The region is mainly covered by monsoon evergreen broad-leaf forest with limited coniferous forest (Yi et al. 2007). The site is a small intermontane basin with an area of $\sim 3$ ha in southwest Gaoyao $\left(22^{\circ} 53^{\prime} 19^{\prime \prime} \mathrm{N}, 112^{\circ} 19^{\prime} 66^{\prime \prime} \mathrm{E}\right)$. The ancient forest was found buried in the soil of the basin at a depth of $<1.0 \mathrm{~m}$. The sampling profile is $5.66 \mathrm{~m}$ thick and can be divided into 6 layers. The uppermost layer (layer A) is $75 \mathrm{~cm}$ thick and composed of silty clay mixing with charcoal and plant detritus. In this layer, many well-preserved standing stumps were found (Figure 2a). Below this were 3 humic layers (layers B, D, F), each filled with crossing buttress roots and trunks. Humic layers were interrupted by 2 white-gray silty clay layers (layers C, E) with thicknesses of about 27 and $36 \mathrm{~cm}$, respectively (Figures 2b,c). We took 72 samples, including 40 stump samples upstanding in layer A, 25 sedimentary samples, and 7 gas samples that were collected using a hand pump (Mityvac) with $16 \mathrm{~mL}$ in volume in other layers.

\section{METHODS}

Sedimentary samples were first dried by a freeze dryer (ALPHA 1-2LDplus). About $5 \mathrm{mg}$ of fine roots (diameter $<0.5 \mathrm{~mm}$ ) with the same color as the sedimentary samples in humic layers, and charcoal and plant detritus from the top layer were picked out. About 2-3 g of sedimentary subsample was treated with $2 \mathrm{M} \mathrm{HCl}$ to eliminate cohesive carbonate, and then rinsed with distilled water. The subsample was then treated through $0.2 \mathrm{M} \mathrm{NaOH}$ and $1 \mathrm{M} \mathrm{HCl}$ successively. Fine roots, charcoals, stumps, and plant detritus samples were treated in the following way. Pretreated subsamples were dried at $70{ }^{\circ} \mathrm{C}$ in an oven, then the subsamples were ground to mix well. Samples were placed into quartz tubes in the presence of silver wire and cupric oxide wire (CuO). After pumping down under vacuum and sealing using a gas torch, samples in sealed tubes were combusted at $850{ }^{\circ} \mathrm{C}$ in a muffle furnace for $2 \mathrm{hr}$ to transform the organic carbon (OC) into $\mathrm{CO}_{2}$ gas. The tubes were then cracked open in a tube cracker to release the $\mathrm{CO}_{2}$ gas, which was purified using liquid $\mathrm{N}_{2}\left(-196{ }^{\circ} \mathrm{C}\right)$ and a liquid $\mathrm{N}_{2}$ + ethanol mixture trap $\left(-78^{\circ} \mathrm{C}\right)$ in the vacuum system. The purified $\mathrm{CO}_{2}$ was then transferred to a known-volume reservoir and quantified by measuring the $\mathrm{CO}_{2}$ pressure. Successively, the purified 


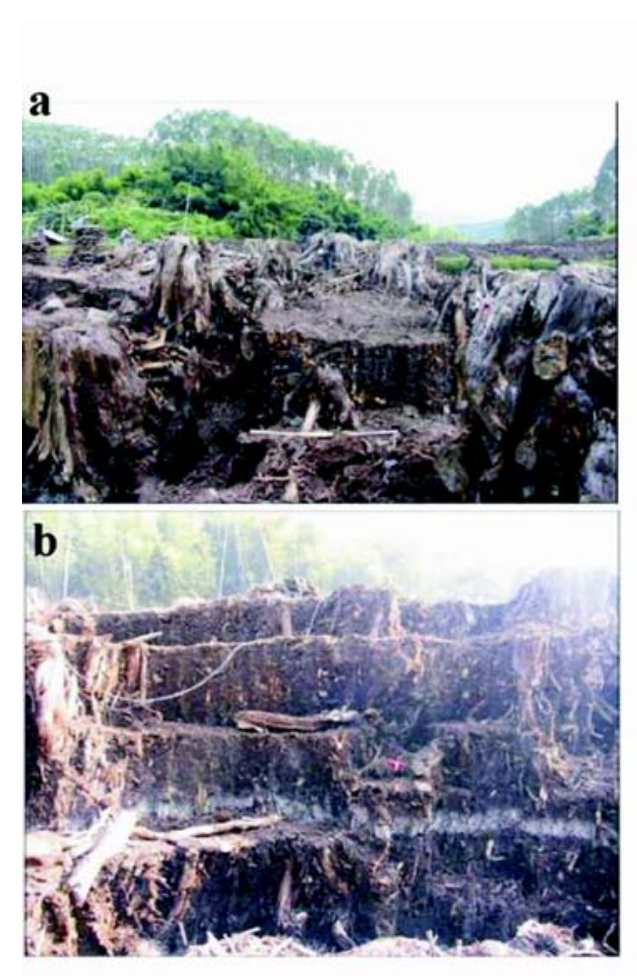

Slate-Grey silty clay

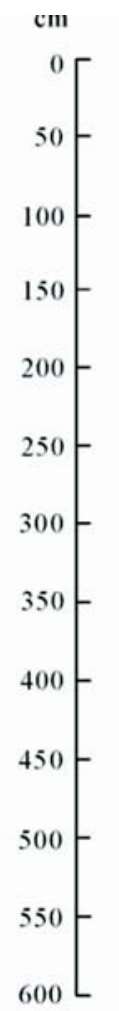

Humic soil

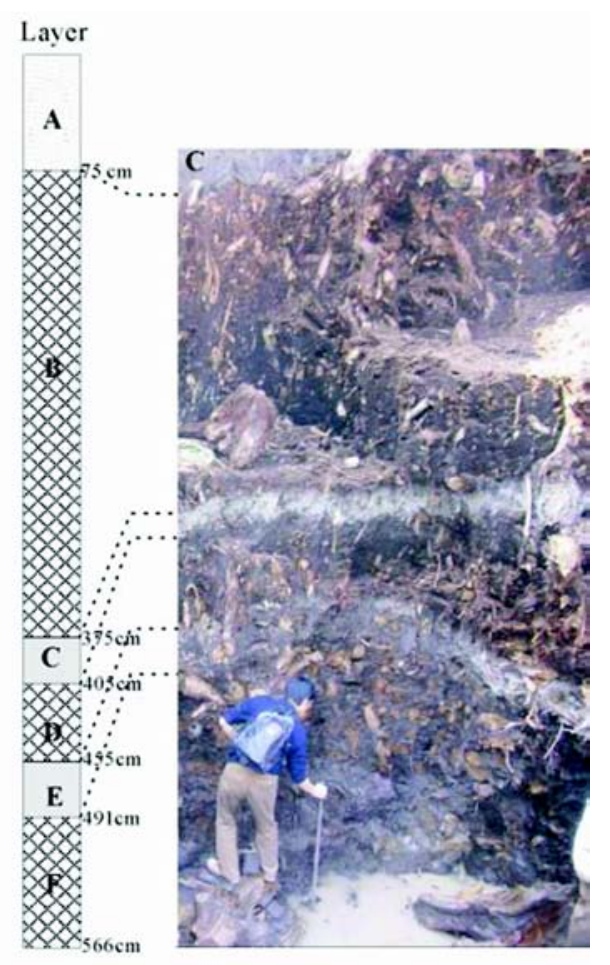

White-grey silty clay

Figure 2 Sampling profile at Gaoyao, Guangdong, south China: (a) upstanding stumps in the surface layer; (b), (c) field sampling profile of the ancient forest.

$\mathrm{CO}_{2}$ was divided into 2 portions with 1 portion containing $0.5-1.0 \mathrm{mg} \mathrm{C}$ for the preparation of graphite targets using the method developed by Xu et al. (2007). The other portion was frozen in a vacuumed tube and sealed for stable carbon isotope analysis. The gas samples were purified and divided into 2 portions for analysis using the method above soon after they were sent back to the laboratory.

Pretreatment and graphite preparations were carried out at the accelerator mass spectrometry (AMS) radiocarbon lab in the Key Laboratory of Isotope Geochronology and Geochemistry, Chinese Academy of Sciences (CAS). Graphite targets were measured using AMS at the State Key Laboratory of Nuclear Physics and Technology, Peking University. The ${ }^{14} \mathrm{C}$ data were calibrated using CALIB 5.01 (Stuiver and Reimer 1993). The organic carbon (OC) content was determined by the amount of carbon in $\mathrm{CO}_{2}$ and the initial amount of sample used in the $\mathrm{CO}_{2}$ extraction. $\delta^{13} \mathrm{C}$ of the purified $\mathrm{CO}_{2}$ gas was determined using a Finnigan MAT-251 mass spectrometer with a precision of $\pm 0.2 \%$ in the State Key Laboratory of Loess and Quaternary Geology, Chinese Academy of Sciences in Xi'an. Results are reported as $\delta^{13} \mathrm{C}$ with the international Pee Dee belemnite (PDB) standard.

\section{RESULTS}

${ }^{14} \mathrm{C}$ data, OC content, and $\mathrm{OC} \delta^{13} \mathrm{C}$ for the ancient forest profile at Gaoyao are shown in Table 1 . The ${ }^{14} \mathrm{C}$ ages of OC illustrated a typical increase with depth. The oldest ${ }^{14} \mathrm{C}$ age of OC for the sampled 
profile is $4.9 \mathrm{ka}$. Although the ${ }^{14} \mathrm{C}$ ages of fine roots showed an increase in age with depth, they were younger and less in a time sequence than the OC ones. The ${ }^{14} \mathrm{C}$ ages of charcoals and plant detritus found in layer A were similar to those of the OC (Figure 3).

Table $1{ }^{14} \mathrm{C}$ data, OC content, and $\mathrm{OC} \delta^{13} \mathrm{C}$ for the ancient forest profile at Gaoyao. ${ }^{\mathrm{a}}$

\begin{tabular}{|c|c|c|c|c|c|c|c|c|c|c|}
\hline Lab nr & Field nr & $\begin{array}{l}\text { Depth } \\
\text { (cm) }\end{array}$ & $\begin{array}{l}{ }^{14} \mathrm{C} \text { age } \\
\mathrm{BP}\end{array}$ & $\begin{array}{l}{ }^{14} \mathrm{C} \text { age } \\
\text { cal BP }\end{array}$ & $\begin{array}{l}\text { OC } \\
\delta^{13} \mathrm{C} \\
(\%)\end{array}$ & $\begin{array}{l}\text { OC } \\
\text { content } \\
(\%)\end{array}$ & Lab nr & Field nr & $\begin{array}{l}{ }^{14} \mathrm{C} \text { age } \\
\mathrm{BP}\end{array}$ & $\begin{array}{l}{ }^{14} \mathrm{C} \text { age } \\
\text { cal BP }\end{array}$ \\
\hline GZ1126 & GY-S-1 & 566 & $4341 \pm 62$ & $4910 \pm 64$ & -30.87 & 28.44 & GZ1114 & GY-R-1 & $3649 \pm 47$ & $3947 \pm 48$ \\
\hline GZ1134 & GY-S-2 & 541 & $4249 \pm 51$ & $4839 \pm 26$ & -30.83 & 28.07 & GZ1115 & GY-R-2 & $3911 \pm 52$ & $4355 \pm 67$ \\
\hline GZ1135 & GY-S-3 & 516 & $4227 \pm 54$ & $4731 \pm 30$ & -29.97 & 34.61 & GZ1116 & GY-R-3 & $3815 \pm 63$ & $4220 \pm 77$ \\
\hline GZ1136 & GY-S-4 & 491 & $3885 \pm 49$ & $4347 \pm 63$ & -30.3 & 10.08 & GZ1117 & GY-R-4 & $3667 \pm 41$ & $4057 \pm 26$ \\
\hline GZ1137 & GY-S-5 & 473 & $3892 \pm 41$ & $4351 \pm 62$ & -27.77 & 8.84 & GZ1118 & GY-R-5 & $3618 \pm 62$ & $3916 \pm 73$ \\
\hline GZ1138 & GY-S-6 & 455 & $3730 \pm 40$ & $4017 \pm 25$ & -29.91 & 10.54 & GZ1119 & GY-R-6 & $3487 \pm 48$ & $3743 \pm 41$ \\
\hline GZ1139 & GY-S-7 & 430 & $3700 \pm 31$ & $4019 \pm 33$ & -29.97 & 38.26 & GZ1120 & GY-R-7 & $3543 \pm 45$ & $3859 \pm 37$ \\
\hline GZ1140 & GY-S-8 & 405 & $3412 \pm 38$ & $3658 \pm 45$ & -30.72 & 20.34 & GZ1121 & GY-R-8 & $3163 \pm 55$ & $3398 \pm 51$ \\
\hline GZ1141 & GY-S-9 & 390 & $3136 \pm 38$ & $3368 \pm 34$ & -28.15 & 1.00 & GZ1122 & GY-R-9 & $2733 \pm 49$ & $2822 \pm 46$ \\
\hline GZ1142 & GY-S-10 & 375 & $3280 \pm 29$ & $3539 \pm 19$ & -30.24 & 7.51 & GZ1123 & GY-R-10 & $3154 \pm 45$ & $3379 \pm 33$ \\
\hline GZ1143 & GY-S-11 & 350 & $3256 \pm 31$ & $3466 \pm 22$ & -30.06 & 59.56 & GZ1124 & GY-R-11 & $3094 \pm 44$ & $3343 \pm 26$ \\
\hline GZ1144 & GY-S-12 & 325 & $3155 \pm 33$ & $3382 \pm 25$ & -29.77 & 64.00 & GZ1125 & GY-R-12 & $2987 \pm 50$ & $3196 \pm 59$ \\
\hline GZ1145 & GY-S-13 & 300 & $3138 \pm 34$ & $3370 \pm 32$ & -29.71 & 43.01 & GZ1105 & GY-R-13 & $2847 \pm 45$ & $2942 \pm 65$ \\
\hline GZ1146 & GY-S-14 & 275 & $3004 \pm 34$ & $3211 \pm 54$ & -29.03 & 61.32 & GZ1106 & GY-R-14 & $2865 \pm 41$ & $3004 \pm 62$ \\
\hline GZ1152 & GY-S-15 & 250 & $2849 \pm 33$ & $2963 \pm 41$ & -30.34 & 59.52 & GZ1107 & GY-R-15 & $2283 \pm 44$ & $2328 \pm 22$ \\
\hline GZ1153 & GY-S-16 & 225 & $2499 \pm 43$ & $2548 \pm 55$ & -30.53 & 57.01 & GZ1108 & GY-R-16 & $2257 \pm 44$ & $2211 \pm 31$ \\
\hline GZ1154 & GY-S-17 & 200 & $2364 \pm 34$ & $2355 \pm 13$ & -30.48 & 41.91 & GZ1109 & GY-R-17 & $2047 \pm 43$ & $2004 \pm 57$ \\
\hline GZ1155 & GY-S-18 & 175 & $2302 \pm 41$ & $2332 \pm 24$ & -29.94 & 63.60 & GZ1110 & GY-R-18 & $1759 \pm 42$ & $1665 \pm 57$ \\
\hline GZ1156 & GY-S-19 & 150 & $2267 \pm 34$ & $2325 \pm 18$ & -29.55 & 57.44 & GZ1111 & GY-R-19 & $2162 \pm 45$ & $2147 \pm 36$ \\
\hline GZ1157 & GY-S-20 & 125 & $2107 \pm 34$ & $2084 \pm 44$ & -29.10 & 61.32 & GZ1112 & GY-R-20 & $2068 \pm 44$ & $2031 \pm 41$ \\
\hline GZ1158 & GY-S-21 & 100 & $2025 \pm 41$ & $1966 \pm 42$ & -29.48 & 53.07 & GZ1113 & GY-R-21 & $1970 \pm 49$ & $1914 \pm 39$ \\
\hline GZ1159 & GY-S-22 & 75 & $1091 \pm 38$ & $985 \pm 26$ & -27.00 & 7.03 & & & & \\
\hline GZ1160 & GY-S-23 & 50 & $672 \pm 33$ & $658 \pm 12$ & -26.55 & 3.70 & & & & \\
\hline GZ1161 & GY-S-24 & 25 & $388 \pm 33$ & $470 \pm 32$ & -26.08 & 4.03 & & & & \\
\hline GZ1162 & GY-S-25 & 0 & $217 \pm 34$ & $288 \pm 15$ & -26.32 & 3.30 & & & & \\
\hline
\end{tabular}

${ }^{\mathrm{a} 14} \mathrm{C}$ data were calibrated by CALIB 5.01 (Stuiver and Reimer 1993). Errors are $\pm 1 \sigma$.

The OC contents are significantly higher in the humic layers than in the silty clay layers, while the OC $\delta^{13} \mathrm{C}$ values positively shift when the humic layers change into the silty clay layers (Figure 4).

\section{DISCUSSION}

\section{Historical Evolution of the Ancient Forest at Gaoyao}

The main reason for the discrepancy between the ${ }^{14} \mathrm{C}$ ages of fine roots and $\mathrm{OC}$ is that the fine roots grew underground within sediments that are older, and were preserved under the reducing environment. The ${ }^{14} \mathrm{C}$ ages derived from OC are considered to form an accurate chronology for the evolution of the ancient forest because the litters entered the sediment soon after they decomposed above the ground. Therefore, the ${ }^{14} \mathrm{C}$ ages of OC are expected to establish a chronology for the evolution of the ancient forest. 


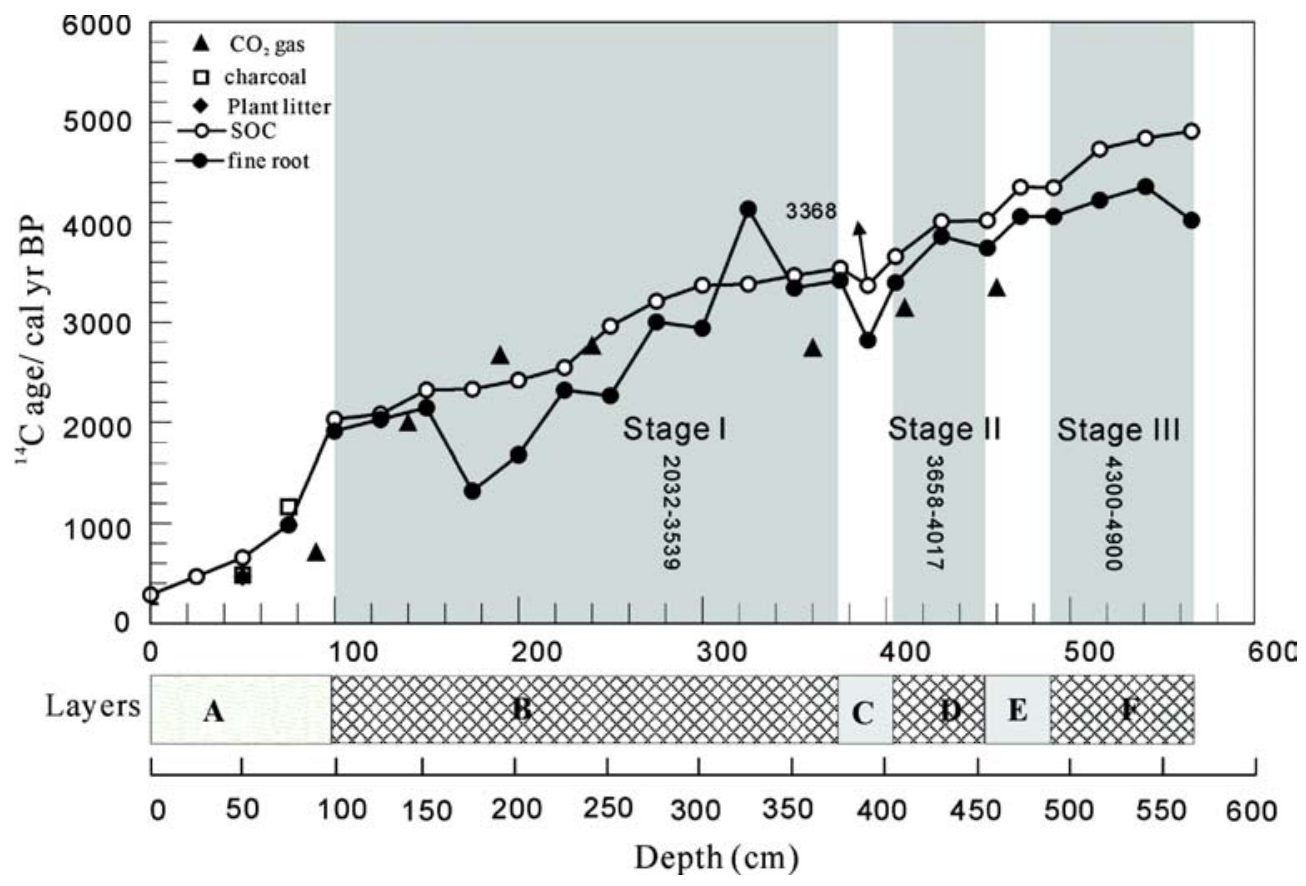

Figure $3{ }^{14} \mathrm{C}$ chronology of the ancient forest at the Gaoyao site

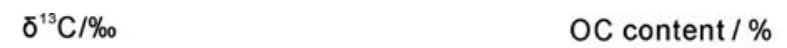

$\begin{array}{lllllllllll}\text { Layers } & -24 & -26 & -28 & -30 & -32 & 0 & 20 & 40 & 60 & 8 \mathrm{C}\end{array}$

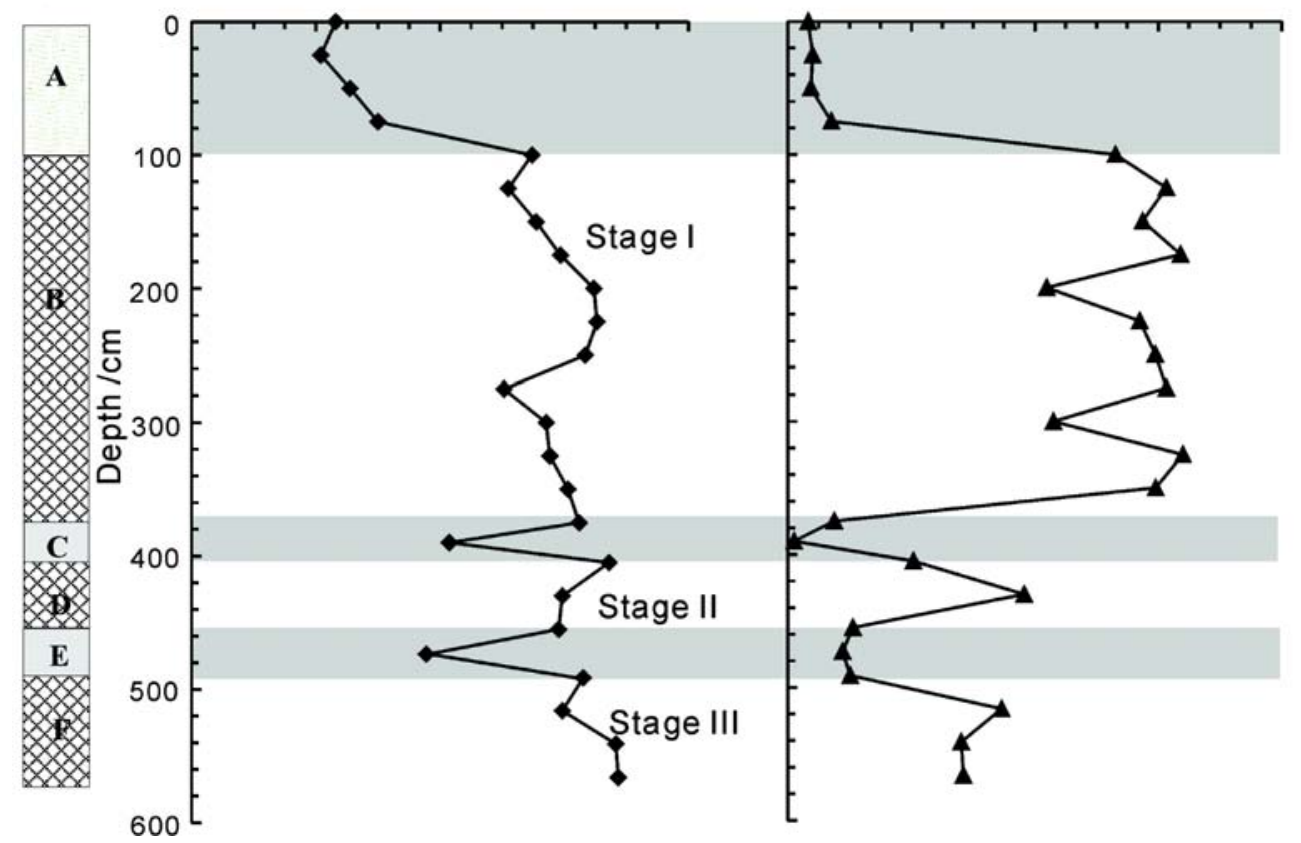

Figure 4 Down-profile variations of $\delta^{13} \mathrm{C}$ value and OC content at the Gaoyao site 
Investigation of the ${ }^{14} \mathrm{C}$ ages taken from bark and core samples of upright tree stumps found in the top layer showed that the last Glyptostrobus pensilis forest developed between $1.5 \mathrm{ka}$ and $1.1 \mathrm{ka}$, lasting for $\sim 400 \mathrm{yr}$. Three humic layers represented another 3 stages for the G. pensilis forest (Figure 3). Stage I (1.00-3.75 m), Stage II (4.00-4.73 m), and Stage III (4.91-5.66 m) - with ${ }^{14} \mathrm{C}$ ages ranging from $2.0 \mathrm{ka}$ to $3.5 \mathrm{ka}, 3.6-4.0 \mathrm{ka}$, and 4.3-4.9 ka-lasted for about 1500, 400, and 600 yr, respectively.

Three stages of the ancient forest developed in the wetland. As Figure 4 illustrates, the $\mathrm{OC} \delta^{13} \mathrm{C}$ values- which varied from $-29.10 \%$ o to $-30.53 \%$ o, $-29.97 \%$ to $-30.72 \%$, and $-29.97 \%$ o to $-30.87 \%$ o in the humic layers B, D, and F, respectively-remained stable and similar within and between each layer. Combined with the high OC content in these layers, most of the OC was preserved due to a reducing environment. Considering the habitat of the living $G$. pensilis and the landscape, the study area was most likely a wetland during the 3 stages.

\section{Comparison of the Ancient Forest Developed in Gaoyao and Sihui}

A previous study (Ding et al. 2009) showed that the ancient forest in Sihui began to develop at $\sim 4.2$ ka and died out at $\sim 3.3 \mathrm{ka}$. This corresponds to Stage II of the ancient forest that developed in Gaoyao (Figure 5), implying that the ancient forest, as well as the wetland in Sihui, formed later but disappeared earlier than the forest in Gaoyao. The reason for the difference may be related to the different landforms. Although Sihui and Gaoyao have the same climate conditions, the Gaoyao area is a small intermontane basin, whereas there is a lowland in Sihui.

As indicated by the pollen data from Huangsha profile near the study area, an evergreen assemblage including Elaeocarpus, Quercus, Chamionii, Altingia, Apocynaceae, and Moreceae displayed a broad high percentage from 5.0 to $1.6 \mathrm{ka}$, indicating increased precipitation during that period (Li et al. 1991). Corresponding to the 3 stages (I, II, and III) of the ancient forest, the pollen percentage reached 3 maxima at 4.0,3.0, and $2.0 \mathrm{ka}$. With the increasing precipitation, the evergreen assemblage reached a high percentage in Huangsha at around 5.0 ka. Meanwhile in our study area, the wetland was formed and then the ancient forest flourished for the first time.

\section{Formation of the White-Gray Silty Layer}

Variations in the OC contents and the OC $\delta^{13} \mathrm{C}$ could reflect the decomposition state of OC and further indicate changes in the sedimentary environment (Chen et al. 2005). As shown in Figure 4 and Table 1, the OC content ranges from 3.30\% to $7.03 \%$ in layer A, lower than that in the humic layers, but close to the content in layers $\mathrm{C}$ and $\mathrm{E}$ (white-gray silty layers), which ranges from $1.00 \%$ to $7.51 \%$ and $8.84 \%$ to $10.54 \%$, respectively.

The above difference was also reflected in the OC $\delta^{13} \mathrm{C}$ (Figure 4, Table 1). Compared to the humic layers, the OC $\delta^{13} \mathrm{C}$ in layers $\mathrm{A}, \mathrm{C}$, and $\mathrm{E}$ is positively shifted significantly, especially in the center of the silty layers. Great variations in the OC contents and the $\mathrm{OC} \delta^{13} \mathrm{C}$ between different layers indicated the different sedimentary environments.

The sedimentary environment of layers $\mathrm{A}, \mathrm{C}$, and $\mathrm{E}$ is more difficult to establish. There are 2 possibilities for the origin of the silty layers: the sediment being deposited in situ or from the outside. As shown in Figure 2, the thicknesses of silty layers $\mathrm{C}$ and $\mathrm{E}$ throughout the area (at least 3 profiles) were similar. Given the difference in age of silty layers $\mathrm{C}$ and $\mathrm{E}$ of 300 and $100{ }^{14} \mathrm{C} \mathrm{yr}$, if the silty layers consisted of foreign matter carried from surroundings, the lower place would have formed thicker silty sediments and the OC contents would be close to those in humic layers in the reducing environment. Therefore, we consider that the silt has not been transported and mainly formed in situ. 


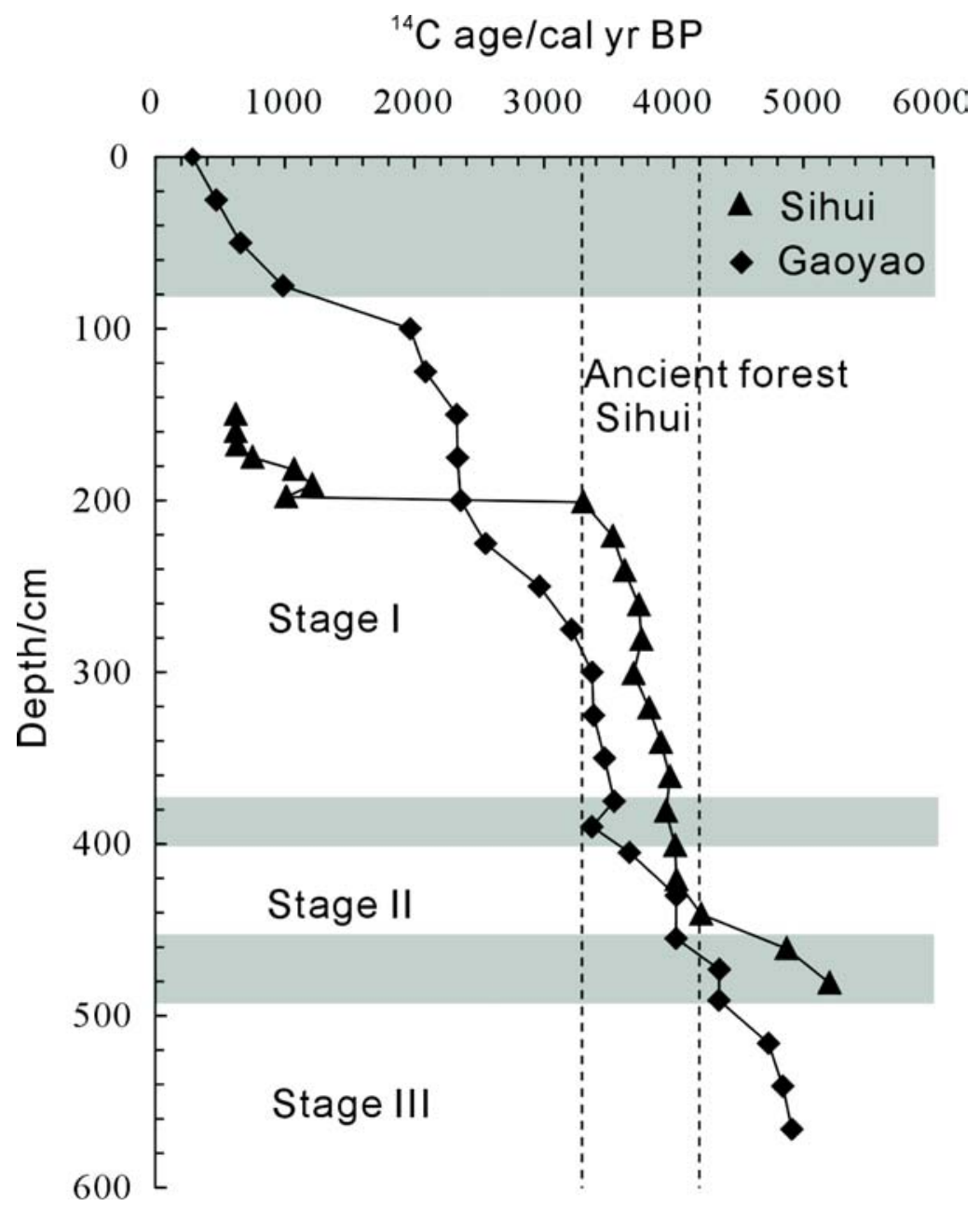

Figure 5 Comparison of ${ }^{14} \mathrm{C}$ chronology between ancient forests in Gaoyao and Sihui. The dashed lines represent the onset and termination of the ancient forest at Sihui.

\section{Drought Events and Precipitation Recorded by the Ancient Forest}

In the study area, the wetlands gave way to dry land at about 4.3, 3.6, and 2.0 ka BP, respectively. These changes were likely related to climate events since the mid-Holocene as reported elsewhere (Bond et al. 1997; deMenocal et al. 2000). As shown in Figure 6, the drought events reflected from the historical evolution were consistent with the ice-rafting and cold events 3, 2, 1 recorded in the North Atlantic and north Africa, respectively (Bond et al. 1997; deMenocal et al. 2000). Cooler and drier climate also occurred in the Asian monsoon climate zones during the same periods. Stalagmites from Dongge Cave indicate an abrupt decline in precipitation, with $\delta^{18} \mathrm{O}$ making a sharp positive shift at about 4.3, 3.5, and $1.7 \mathrm{ka}$ (Wang et al. 2005). When the East Asian summer monsoon weakened, the strengthened winter monsoon carried more Ti into the sediments in Huguang Maar Lake near the study area, resulting in high peaks of Ti content at about 4.3, 3.0, and $2.0 \mathrm{ka}$, respectively (Yancheva et al. 2007). During these drought events, the wetland changed into dry land, and in such an environment the OC content decreased dramatically and $\mathrm{OC} \delta^{13} \mathrm{C}$ shifted positively due 


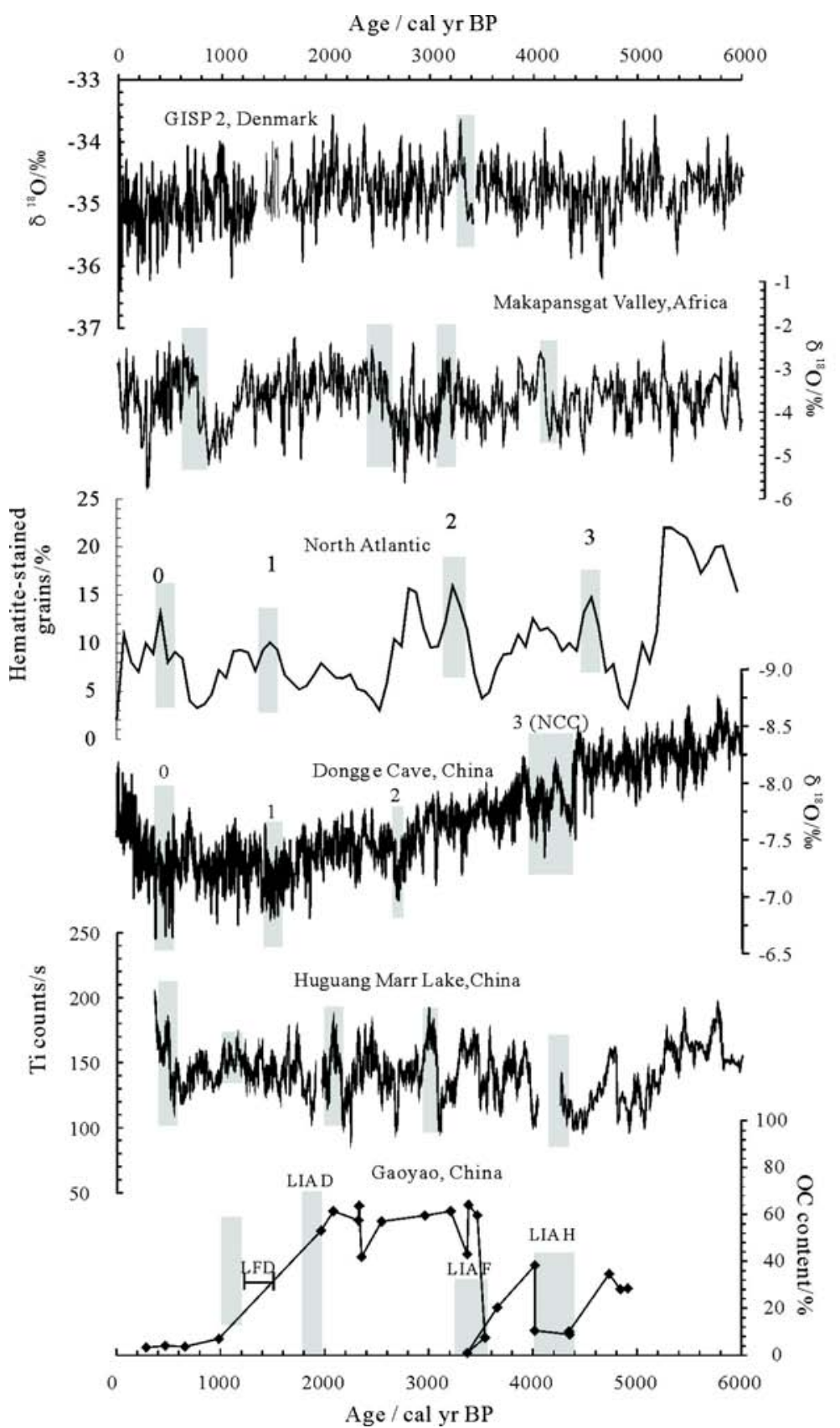

Figure 6 Comparison between OC content and other high-resolution proxy records around the world: (a) GISP2 $\delta^{18} \mathrm{O}$ record from Greenland (Stuiver et al. 1995); (b) stalagmite $\delta^{18} \mathrm{O}$ record from Makapansgat Valley, South Africa (Holmgren et al. 2003); (c) hematite-stained grains (\%) record from North Atlantic (Bond et al. 2001); (d) stalagmite $\delta^{18} \mathrm{O}$ record from Dongge Cave, south China (Wang et al. 2005); (e) titanium data from Huguang Maar lake, south China (Yancheva et al. 2007); (f) climate events record from ancient forest in Gaoyao, south China (this study). LIA = little ice age, according to $\mathrm{Xu}$ (1998); LFD = last forest developed. 
to decomposition of the organic matter. These cold and drought events were also in agreement with little ice ages (H, F, D) speculated from written histories (Xu 1998). Termination of the ancient forest evolution at 1.1 ka likely represented another climate fluctuation before the Little Ice Age that occurred between AD 1300 and 1850 (Xu 1998; deMenocal et al. 2000). It was mostly noted in the low-latitude areas (Haug et al. 2001; Yancheva et al. 2007) and corresponded to the final stage of the Maya collapse (Hodell et al. 1995).

The shifts between wetland and dry land reoccurred about every $1000{ }^{14} \mathrm{C} \mathrm{yr}$, close to the approximate period of 1500 recorded in the North Atlantic area (Bond et al. 1997), suggesting that the climate in south China varies not only in millennial scale but also in centennial scale.

The historical evolution of the ancient forests at Gaoyao, combined with the one at Sihui, represents a long-term trend for the precipitation in the region, which has been related to the East Asian summer monsoon since the mid-Holocene in south China. As inferred from the shifts between wetland and dry land in the study area, precipitation in south China increased around the mid-Holocene as evidenced by the formation of the wetland in Gaoyao at about $5.0 \mathrm{ka}$. Despite being interrupted by the drought event occurring at $4.3 \mathrm{ka}$, the continuous increase of precipitation resulted in the development of wetlands in Sihui at about 4.2 ka. Precipitation then decreased gradually since $3.6 \mathrm{ka}$, when the pollen percentage of Glyptostrobus pensilis reached almost $100 \%$ at Sihui. This finding is consistent with other paleoclimatic records in south China, suggesting the maximum East Asian summer monsoon precipitation occurred at around $3.0 \mathrm{ka}$ (An et al. 2000).

\section{CONCLUSION}

The ancient forest at Gaoyao developed earlier than 5.0 ka and ended at $~ 1.1 \mathrm{ka}$. As evidenced from the historical evolution of the ancient forest, the climate since the mid-Holocene in south China was unstable and punctuated by 4 climate events, which occurred at 4.3, 3.6, 2.0, and $1.1 \mathrm{ka}$, with durations of $\sim 1000$ yr. These events may be correlated with other high-resolution records of cooling and drought events both in low- and high-latitude areas. The precipitation decreased since $3.6 \mathrm{ka}$, which caused the disappearance of the wetland and associated ancient forest around $3.3 \mathrm{ka}$ at Sihui, and finally, the termination of the wetland at 2.0 ka at Gaoyao.

\section{ACKNOWLEDGMENTS}

We thank Dr Zhang Jinping, South China Botanical Garden, Chinese Academy of Sciences, for his support during the field sampling. This work was supported by the Open Funds of State Key Laboratory of Organic Geochemistry (grant no. OGL-200607) and National Basic Research Program of China (grant no. 2005CB422004).

\section{REFERENCES}

An ZS, Porter SC, Kutzbach JE, Wu XH, Wang SM, Liu XD, Li XQ, Zhou WJ. 2000. Asynchronous Holocene optimum of the East Asian monsoon. Quaternary Science Reviews 19(8):743-62.

Bond G, Showers W, Cheseby M, Lotti R, Almasi P, deMenocal P, Priore P, Cullen H, Hajdas I, Bonani G. 1997. A pervasive millennial-scale cycle in North Atlantic Holocene and glacial climates. Science 278(5341):1257-66.

Bond G, Kromer B, Beer J, Muscheler R, Evans MN, Showers W, Hoffmann S, Lotti-Bond R, Hajdas I, Bonani G. 2001. Persistent solar influence on North At-

lantic climate during the Holocene. Science 294(5549):2130-6.

Chen QQ, Shen CD, Sun YM, Peng SL, Yi WY, Li ZA, Jiang MT. 2005. Spatial and temporal distribution of carbon isotopes in soil organic matter at the Dinghushan Biosphere Reserve, South China. Plant and Soil 273(1-2):115-28.

deMenocal P, Ortiz J, Guilderson T, Sarnthein M. 2000. Coherent high- and low- latitude climate variability during the Holocene warm period. Science 288(5474): 2198-202.

Ding P, Shen CD, Wang N, Yi WX, Liu KX, Ding XF, Fu 
DP. 2009. Carbon isotopic composition and its implications on paleoclimate of the underground ancient forest ecosystem in Sihui, Guangdong. Science in China Series D 52(5):638-46.

Haug GH, Hughen KA, Sigman DM, Peterson LC, Röhl U. 2001. Southward migration of the intertropical convergence zone through the Holocene. Science 293(5533):1304-8.

Hodell DA, Curtis JH, Brenner M. 1995. Possible role of climate in the collapse of Classic Maya civilization. Nature 375(6530):391-4.

Holmgren K, Lee-Thorp JA, Cooper GRJ, Lundblad K, Partridge TC, Scott L, Sithaldeen R, Talma AS, Tyson PD. 2003. Persistent millennial-scale climatic variability over the past 25,000 years in southern Africa. Quaternary Science Reviews 22(21-22):2311-26.

Li FG, Xia NH. 2004. The geographical distribution and cause of threat to Glyptostrobus pensilis (Taxodiaceae). Journal of Tropical and Subtropical Botany 12:13-20. In Chinese with English abstract.

Li PR, Zheng JS, Fang GX. 1991. Quaternary Geology in the Guangzhou Area. Guangzhou: Hunnan University of Science and Technology Press. p 53-81. In Chinese.

Li PR, Cui HT, Tan HZ. 2001. A study on Holocene buried timbers in Guangdong. Tropical Geography 21: 195-7. In Chinese with English abstract.

Stuiver M, Reimer PJ. 1993. Extended ${ }^{14} \mathrm{C}$ data base and revised CALIB $3.0^{14} \mathrm{C}$ age calibration program. $\mathrm{Ra}$ diocarbon 35(1):215-30.

Stuiver M, Grootes PM, Braziunas TF. 1995. The GISP2 $\delta^{18} \mathrm{O}$ climate record of the past 16,500 years and the role of the sun, ocean and volcanoes. Quaternary Research 44(3):341-54.

Wang YJ, Chen H, Edwards RL, He YQ, Kong XG, An ZS, Wu JY, Kelly MJ, Dykoski CA, Li XD. 2005. The
Holocene Asian monsoon: links to solar changes and North Atlantic climate. Science 308(5723):854-7.

Xu JH. 1998. Sun, climate, famine and nationality migrations. Science in China Series D 28:366-84. In Chinese.

Xu XM, Trumbore SE, Zheng SH, Southon JR, McDuffee KE, Luttgen M, Liu JC. 2007. Modifying a sealed tube zinc reduction method for preparation of AMS graphite targets: reducing background and attaining high precision. Nuclear Instruments and Methods in Physics Research B 259(1):320-9.

Yancheva G, Norbert NR, Mingram J, Dulski P, Schettler G, Negendank JFW, Liu J, Sigman DM, Peterson LC, Haug GH. 2007. Influence of the intertropical convergence zone on the East Asian monsoon. Nature 445(7123):74-7.

Yi ZG, Fu SL, Yi WM, Zhou GY, Mo JM, Zhang DQ, Ding MM, Wang XM, Zhou LX. 2007. Partitioning soil respiration of subtropical forests with different successional stages in south China. Forest Ecology and Management 243(2-3):178-86.

Yu KF, Liu DS, Shen CD. 2002. High-frequency climatic oscillations recorded in a Holocene coral reef at Leizhou Peninsula, South China Sea. Science in China Series D 45(12):1057-67.

Yu ZY, Peng SL. 1995. The artificial and natural restoration of tropical and subtropical forests. Acta Ecologica Sinica 15(A):1-17. In Chinese with English abstract.

Zhang DE, Lu LH. 2007. Anti-correlation of summer/ winter monsoons? Nature 450(7168):E7-E9.

Zhou HY, Guan HZ, Chi BH. 2007. Record of winter monsoon strength. Nature 450(7168):E10-E11.

Zong YQ. 2004. Mid-Holocene sea-level highstand along the southeast coast of China. Quaternary International 117(1):55-67. 